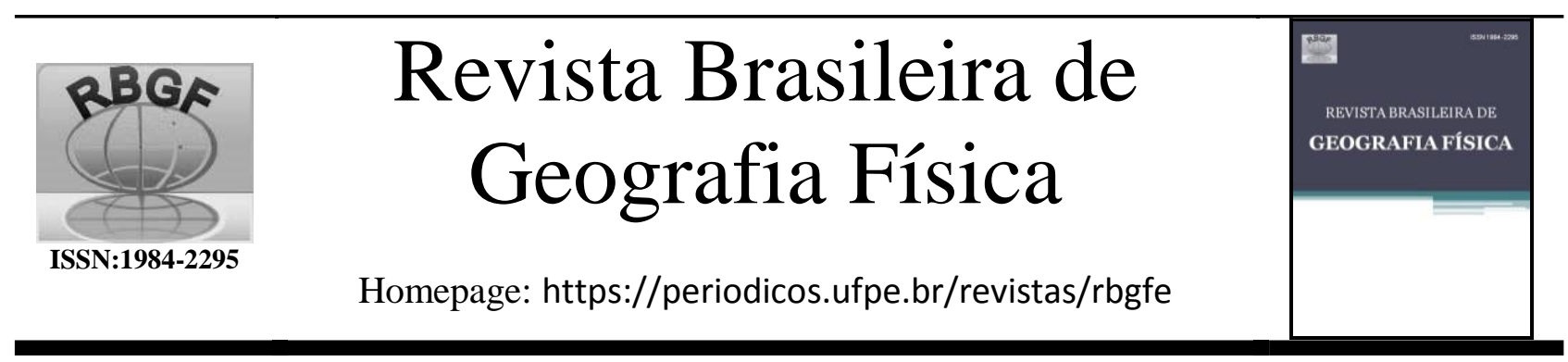

\title{
Caracterização Física e Mineralógica de Materiais Intempéricos na Área Urbana de Juiz de Fora - MG, através de Análise Macroscópica, Difratômetro de Raios-X (DRX) e Microscópio Eletrônico de Varredura (MEV) ${ }^{1}$
}

\author{
Rafaela Teixeira Paula ${ }^{1}$; Geraldo César Rocha ${ }^{2}$ \\ ${ }^{1}$ Mestre em Geografia pela Universidade Federal de Juiz de Fora, Programa de Pós Graduação em Geografia, CEP: 36037000, Juiz deFora (MG), \\ Brasil, Tel: (+5532)99134-1552, e-mail: rafaelatpaula@ gmail.com. \\ ${ }^{2}$ Prof. Dr. do Departamento de Geociências da Universidade Federal de Juiz de Fora, CEP: 36037000, Juiz de Fora (MG), \\ Brasil, Tel: (+5532)9 9139-5202, e-mail: geraldo.rocha@ufff.edu.br. \\ Artigo recebido em 02/05/2020 e aceito em 21/05/2021
}

\section{RESUMO}

Materiais saprolíticos constituem importantes seções no recorte vertical da paisagem. São materiais ainda pouco conhecidos e demandam maior dedicação. Para caracterização destes materiais pode-se fazer uso de técnicas de mineralogia e micromorfologia como a difração de Raios-X (DRX) e o Microscópio Eletrônico de Varredura (MEV). O DRX é uma técnica de caracterização de estruturas cristalinas. O MEV é um tipo de microscópio capaz de produzir imagens de alta resolução da superfície de materiais sólidos. O objetivo é caracterizar amostras de materiais intemperizados de diferentes rochas. Foram selecionados cinco perfis de intemperismo em Juiz de Fora - MG. Os parâmetros utilizados para a análise física e mineralógica foram os seguintes: cor, textura, consistência, rocha de origem e grau de alteração, mineralogia e micromorfologia. A cor é variável entre e intra amostras, é dependente dos minera is constituintes e do grau de alteração. A textura está liga da a os minera is constituintes e seus ta manhos, que são dependentes de seus graus de alteração. A consistência é dependente da resistência dos minera is constituintes e da alteração. As rochas de origem são o quartzito ou o gna isse. Os principais minerais encontrados fora m quartzo, biotita, muscovita e caulinita. Quanto maior a porcentagem de argila, menor a consistência e maior o grau de alteração. A presença de minerais mais resistentes tende a dificultar a pedogênese, resultando em perfis mais arenosos, com poucos minerais de argila e sem atividade biológica. Nos perfis em que predomina o quartzo, apesar da presença desse mineral, o grau de alteração é elevado.

Palavras chave: Mineralogia; Micromorfologia; Materialde intemperismo.

\section{Physical and Mineralogical Characterization of Weathering Materials in the Urban Area of Juiz de Fora - MG through Macroscopic Analysis, X-Ray Diffractometer and Scanning Electron Microscope}

\begin{abstract}
Saprolitic materials are important sections in the vertical cutout of the landscape. These materials are still little known and demand greater dedication. To characterize these materials, we can use mineral and micromorphological techniques such as X-ray diffraction, a technique for characterizing crystalline structures and the Scanning Electron Microscope, a type of microscope capable of producing high-resolution images of the surface of solid materials. The objective is to characterize weathered colors of different stones. Five weathering profiles were selected in Juiz de Fora - MG. The parameters used for physical and mineralogical analysis were as follows: color, texture, consistency, original rock and degree of change, mineralogy and micromorphology. The color is variable, depends on the constituent minerals and the degree of change. The texture is linked to the constituent minerals and their sizes, which depend on their degree of change. The consistency is dependent on the strength of the constituent minerals and the degree of change. The original rocks are
\end{abstract}

$1 *$ Texto extraído de Dissertação de Mestrado

Paula., R., T., Rocha., G., C. 
quartzite and gneiss. The main minerals found were quartz, biotite, muscovite and kaolinite. The higher the clay percentage, the lower the consistency and the greater the degree of change. The presence of more resistant minerals makes pedogenesis difficult, resulting in more sandy profiles, with few clay minerals and without biological activity. In profiles that predominate quartz, despite the presence of this mineral, the degree of change is high.

Keywords: Mineralogy; Micromorphology; Weathering material.

\section{Introdução}

Grande parte do território brasileiro está situado em ambiente tropical, onde o clima provoca a formação de perfis espessos de solos. O intemperismo tem um importante papel na transformação das rochas, formação dos solos e estruturação do relevo. Processos de intemperismo químico, com geração de profundos e complexos perfis saprolíticos e lateríticos, são fenômenos de grande relevância para a compreensão da evolução morfodinâmica das paisagens e caracterização de espessos e diversificados mantos de alteração em regiões intertropicais úmidas e semiúmidas (Ramos, et al, 2020).

O saprolito é um horizonte residual do solo, resultado do intemperismo das rochas e tem presença marcante em ambiente tropical. Sua principal característica é manter a estrutura reliquiar da rochade origem, assim como eventuais descontinuidades, tais como falhas e juntas. Sua espessura e granulometria são variáveis que dependem da posição no relevo e da rocha de origem (Wanderley Neto, 2020). Ocorre abaixo dos horizontes superficiais em regiões de perfil bem evoluído e acima da rocha alterada, aflorando em regiões de perfil pouco evoluído (Rocha, 2018).

Materiais saprolíticos constituem importantes seções no recorte vertical da paisagem, mas são ainda pouco conhecidos e demandam maior estudo. Mineralogia e estrutura são dois dos parâmetros que devem ser investigados para se entender o comportamento destes materiais (Paula \& Rocha, 2020).

A mineralogia predominante no perfil do solo interfere em sua evolução pedológica e é também determinante nas outras propriedades do solo como textura, consistência, grau de alteração etc. (Marcolin \& Calegari, 2020).

A estrutura influencia significativamente $o$ comportamento mecânico do solo. O termo estrutura pode ser conceituado como a combinação do arranjo das partículas componentes, e as forças interpartículas. De um modo geral, todos os solos podem ser considerados como tendo uma estrutura que é mais ou menos pronunciada, dependendo dos processos de deposição e pós-deposição pelos quais um determinado solo foi submetido durante sua vida geológica (Berisavljević \& Berisavljević, 2018).

O desenvolvimento de técnicas de análise para pesquisa geoquímica e mineralógica em exploração mineral tem evoluído nos últimos anos. Analisadores fluorescentes de raios-X e técnicas hiperespectrais foram desenvolvidas comintuito de identificação mineralógica e micromorfológica de diferentes tipos de rocha, minério e materiais de amostra (Sarala \& Koskinen, 2018).

A descrição de solos em escala microscópica foi iniciada em 1938 por Walter Kubiena em seu livro "Micropedologia", que apresenta pela primeira vez a identificação das microestruturas do solo e as interpretações de sua origem e evolução relacionadas aos processos pedogenéticos e reconhece a importância de classificá-las. O uso dessa ciência cresceu na década de 1970, com o desenvolvimento de instrumentos microscópicos mais modernos (De Castro \& Cooper, 2019).

A difração de Raios-X, conhecida como DRX, é uma técnica de caracterizaçãode estruturas cristalinas amplamente utilizada em diversos setores da ciência e tecnologia, como a medicinal, farmacêutica, indústria eletroeletrônica, aeronáutica e espacial, automobilística, petrolífera, metalúrgica entre outras. A aplicação da micromorfologia do solo foi focada em estudos pedogenéticos, e também levam em consideração aspectos geomorfológicos e geológicos. Outros usos desta técnica podem ser encontrados em arqueologia, engenharia, geotecnia e comportamento físico de solos (De Castro \& Cooper, 2019). No campo das Geociências, é utilizada para caracterização mineralógica da rocha e identificação de argilo-minerais (Fonseca Filho \& Carvalho Lopes, 2013).

$O$ método de difração de Raios-X é utilizado para a investigação da estrutura atômica e molecular da matéria e permite a avaliação do tamanho e orientação de microcristais (Barros, 2019). Segundo Costa (2015), essa técnica auxilia na caracterização da micromorfologia do solo e é um estudo importante para compreender a pedogênese e avaliar as práticas agrícolas. A difraçãode Raios-X resulta de um processo em que os raios X são dispersos pelos elétrons dos átomos componentes de um material, sem mudança de 
comprimento de onda, sendo obedecidas certas condições geométricas (Silva, 2013). A natureza dos Raios-X e as condições em que esses difratam permitem o estudo das substâncias cristalinas (Camargo, 1986).

Os átomos dos cristais funcionam como redes de dif raçãopara os Raios-X, o que possibilita que substâncias bem cristalizadas sejam identificadas por essa radiação. Num determinado mineral de estrutura cristalina, os átomos que o compõe funcionam como obstáculos ao serem submetidos aos raios - X (Silva, 2013). Após colidirem com o material, os raios $\mathrm{X}$ mudam a sua direção de propagação, porém, mantém o comprimento de onda da radiação incidente (JENKINS e SNYDER, 1996). Através do ângulo de difração e da intensidade é possível fazer a reprodução atômica do material.

A caracterização física de materiais sólidos ficou mais precisa com a chegada do Microscópio Eletrônico de Varredura - MEV, um tipo especial de microscópioque é capaz de produzir imagens de alta resolução da superfície de qualquer material sólido, possibilitando, de forma rápida, a observação da morfologia de uma amostra sólida (Dedavid, et.al, 2007). No campo da micromorfologia, o MEV é um dos instrumentos mais versáteis disponíveis para a observação e análise de microestruturas e microagregados (Brizzi et al., 2019).

A microscopia eletrônica de varredura permite a obtenção de uma imagem ampliada da amostra a partir da interação de um feixe de elétrons com o material (Mannheimer, 2017). Uma característica importante do MEV é a aparência tridimensional da imagem das amostras, resultado direto da grande profundidade de campo (Monteiro, 2017). Permite, também, o exame em pequenos aumentos e com grande profundidade de foco, o que é extremamente útil, pois a imagem eletrônica complementa a informação dada pela imagem óptica (Dedavid, et.al, 2007).

O objetivo deste trabalho é caracterizar amostras de materiais intemperizados de diferentes rochas com o auxílio das técnicas de Difratometria de Raios-X (DRX) e do Microscópio Eletrônico de Varredura (MEV). Objetiva-se também apontar como a mineralogia e a micromorfologia destes materiais influencia em seu próprio intemperismo e comportamento. Espera-se compreender como a constituição mineralógica e microestrutural dos materiais interfere nas propriedades fúsicas do perfil como um todo. Pressupõe-se que perfis intempéricos provindos de rochas compostas por minerais mais resistentes possuem graus menores de alteração e que essa condição seja resultado de sua constituição e disposição em escala microscópica.

\section{Material e Métodos}

O trabalho pode ser dividido em três etapas: seleção de pontos de estudo e a coleta das amostras em campo; análise física das amostras em laboratório; análise da constituição mineralógica e micromorfológica das amostras em laboratório.

\section{Pontos de estudo}

O presente estudo foi realizado em perfis de intemperismo de rochas situadas na área urbana da cidade de Juiz de Fora, cuja localização está apresentada abaixo (Figura 1).

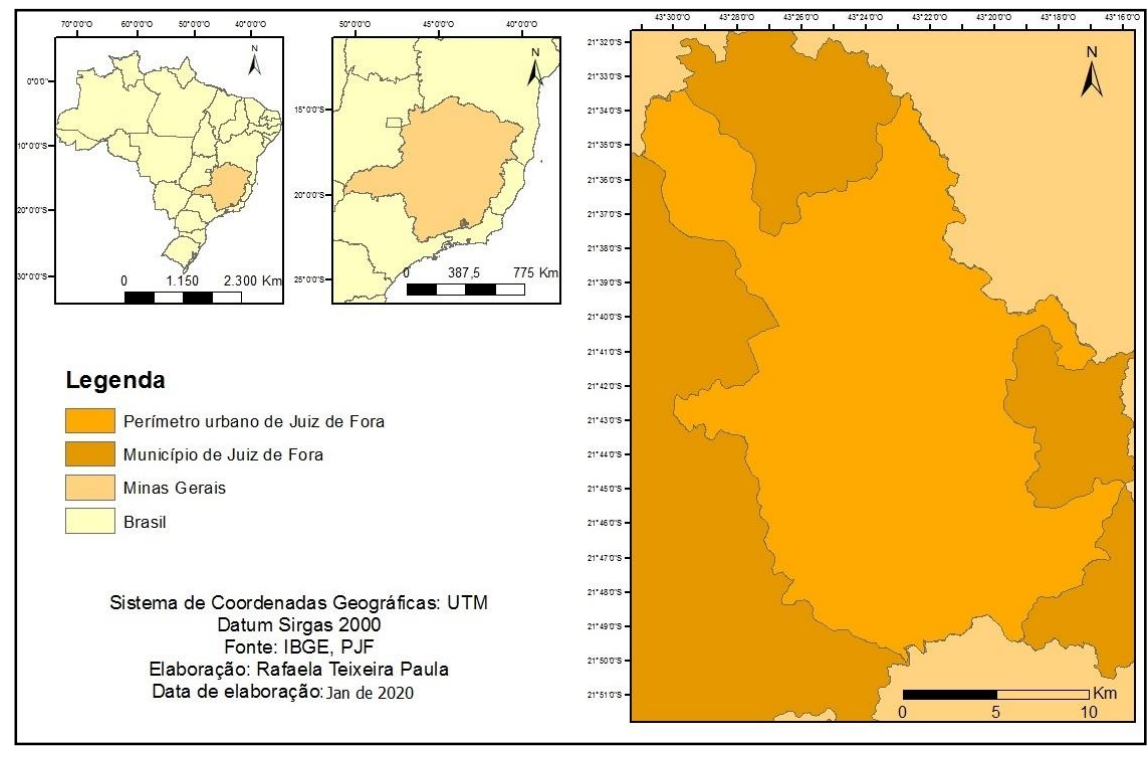

Paula., R., T., Rocha., G., C. 
Figura 1. Localização do perímetro urbano de Juiz de Fora.

Foram selecionados cinco perfis de intemperismo em Juiz de Fora nos bairros Grama, Linhares, Manoel Honório, Santa Cecília e Borboleta, denominados, respectivamente pelas siglas GRAM, LIN, MAN.H., SAN.C. e BOR.. A localização dos pontos de estudos está demarcada no mapa a seguir (Figura 2).

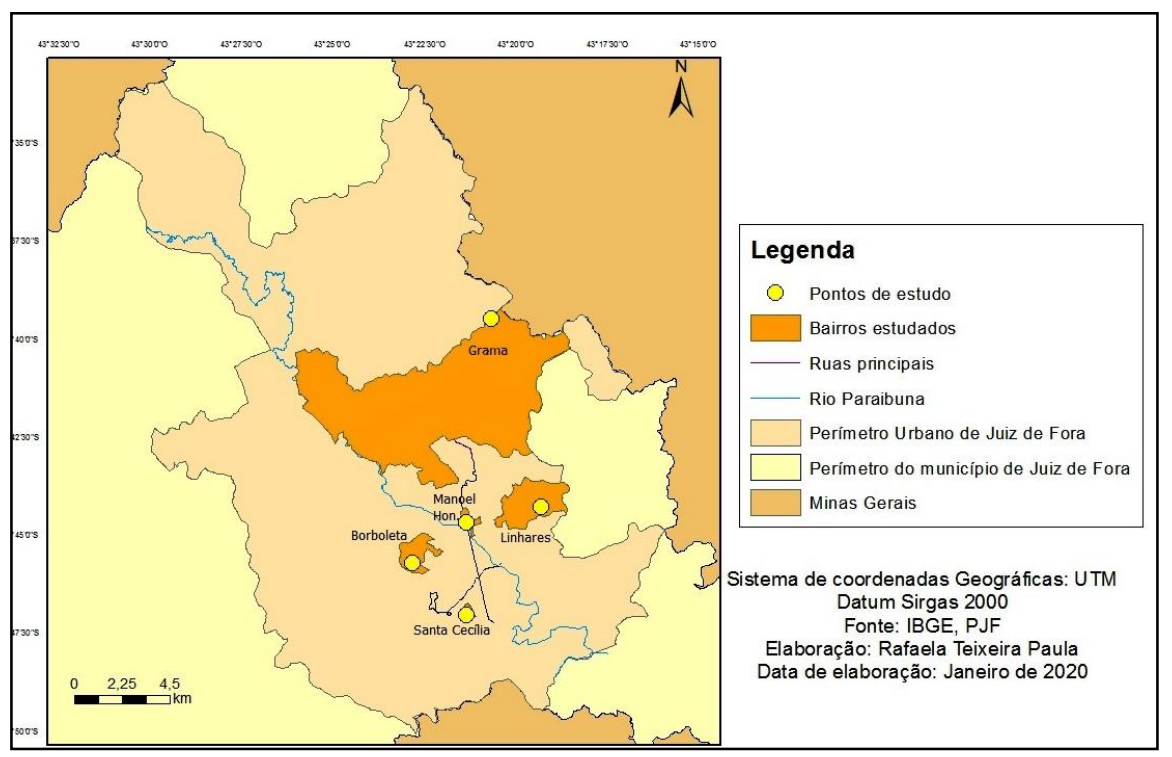

Figura 2. Loca lização dos pontos de estudo.

Análise física

Os parâmetros utilizados para a análise física da amostra foram os seguintes: Cor, textura, consistência, rocha de origem e grau de alteração.

A cor é obtida com o uso da Carta de Munsell (1975) que considera os componentes
Matiz, Valor e Croma. A técnica utilizada para a determinação da textura segue as recomendações de Lemos e Santos (2005). Para determinação da resistência, Guerra (2015) propõe a categorização dos graus de consistência (Tabela 1)

Tabela 1 - Classificação de graus de consistência de saprolitos.

\begin{tabular}{ll}
$\begin{array}{l}\text { Grau de } \\
\text { consistência }\end{array}$ & Significado \\
\hline $\begin{array}{l}\text { Inquebrável } \\
\begin{array}{l}\text { Extremamente } \\
\text { dura }\end{array}\end{array}$ & $\begin{array}{l}\text { fragmentos inquebráveis com as mãos, rúptil apenas com uso de martelo } \\
\text { pedógico e que apresenta sinais de alteração em relação a rocha sã } \\
\text { fram as mãos, mas escavável com martelo pedológico com extrema } \\
\text { dificuldade }\end{array}$ \\
\hline Muito dura & $\begin{array}{l}\text { fragmentos muito dificeis de serem quebrados com as mãos e escaváveis } \\
\text { com martelo pedológico com muita dificuldade }\end{array}$ \\
\hline Dura & $\begin{array}{l}\text { fragmentos quebráveis com as mãos e medianamente fácil de ser } \\
\text { escavável com martelo pedológico }\end{array}$ \\
\hline $\begin{array}{l}\text { Ligeiramente } \\
\text { dura }\end{array}$ & $\begin{array}{l}\text { fragmentos facilmente quebrados com as mãos e facilmente escavável } \\
\text { com martelo pedológico }\end{array}$ \\
\hline Macia/Solta & $\begin{array}{l}\text { fragmentos que não oferecem resistência significativa a pressão com os } \\
\text { dedos ou a escavação }\end{array}$ \\
\hline Variável & com material saprolítico de consistência muito variável \\
\hline
\end{tabular}

Fonte: Guerra, 2015 
A rocha de origem pode ser classificada associando as análises físicas e mineralógicas das amostras de rochas coletadas com as informações do mapa litológico e outras observações encontradas em campo conforme Menezes (1999).

O grau de alteração foi determinado a partir da conciliação e adaptação das propostas metodológicas de Frazão (2012), Ollier (1965) Melton (1965) Thomas (1994), categorizando os graus de alteração a partir da pressão da batida com o martelo geológico, dos pés e das mãos, e a caracterização mineralógica das amostras (Tabela2)

Tabela 2 - Graus de alteração.

\begin{tabular}{cc}
\hline Grau de Alteração & Significado \\
\hline Não alterado & $\begin{array}{c}\text { Material não alterado; não quebra com } \\
\text { martelo geológico }\end{array}$ \\
Fracamente alterado & $\begin{array}{c}\text { Apresenta traços iniciais de alteração, } \\
\text { prevalece minerais primários; quebra com } \\
\text { ajuda do martelo geológico }\end{array}$ \\
Moderadamente alterado & $\begin{array}{c}\text { Presença marcante de minerais primários; } \\
\text { quebra ao chute }\end{array}$ \\
Muito alterado & $\begin{array}{c}\text { Presença marcante de minerais secundários; } \\
\text { quebra com a mão }\end{array}$ \\
fompletamente alterado & $\begin{array}{c}\text { formaño de solo; os minerais secundários } \\
\text { quebra facilmente com a mão }\end{array}$ \\
\hline
\end{tabular}

Fonte: adaptado de Frazão (2012), Ollier (1965) Melton (1965) Thomas (1994)

Análise mineralógica e micromorfológica

Para a análise da constituição mineralógica as amostras foram preparadas e submetidas à análise no difratômetro de Raios-X. As amostras foram moídas em moinho de jarro e depois inseridas em Difratômetro de Raios-X automático de pó, da marca Bruker e modelo D8 Advance. Esse modelo de difratômetro, que analisa a amostra pulverizada, possui um detector móvel que gira em torno da amostra moída, de modo que vários ângulos de reflexão sejam varridos.

Foi empregada a radiação $\mathrm{CuK} \alpha$ usando ótica instrumental de feixe paralelo. A varredura foi no modo step scan, entre 5 a $90^{\circ}$. Foi utilizada uma voltagem de $40 \mathrm{kV}$ e corrente de $40 \mathrm{~mA}$.

Uma fonte de radiação de elevada energia, provoca a excitação dos átomos da substância analisada. Ao ficar sob a ação de uma fonte externa de energia, o átomo, antes em Estado Fundamental (o estado/nível de energia mais baixa (Silva, 2015)), absorve esta energia, promovendo elétrons a níveis mais energéticos, ficando por um momento numa situação instável, chamada "Estado Excitado" (Oliveira, 2011).

Como tudo na natureza, o átomo excitado tende a retornar ao seu estado de estabilidade, voltando a seu estadofundamental (Beckhoff et. al, 2006). Nesse momento ocorre uma emissão de energia de raios, conhecidos como Raios-X "fluorescentes" (Melo Júnior, 2007). Esses raios possuem um comprimento de onda e uma energia específicos para cada elemento do mineral, portanto, através dessa técnica, eles podem ser identificados e quantificados (Oliveira, 2011). O resultado obtido é um difratograma de picos de intensidade de Raios-X x comprimento de onda, únicos de cada material da amostra. Os picos são, então, lidos pelo software Difracc.Eva.

A imagem a seguir (figura 3 ) retrata um exemplo do formato de dif ratograma gerado neste trabalho, seguida do gráfico da porcentagem dos minerais encontrados. 

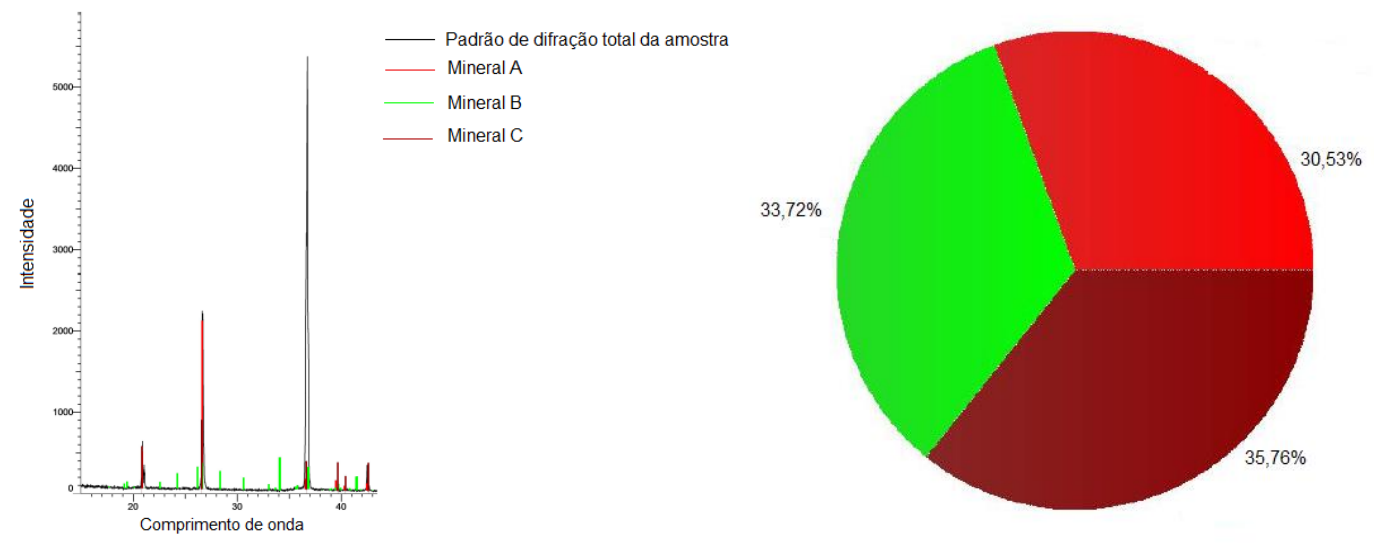

Figura 3. Formato de difra tograma gera do e gráfico da porcentagem dos minerais encontrados.

Cada cor corresponde a um padrão de difração, os picos. A cor preta representa a superposição de todos os picos de cada amostra e é a base para a "comparação" e identificação de cada um dos picos, que correspondem aos diferentes minerais que compõem as amostras, detalhados em colorações diferentes, neste exemplo os minerais $\mathrm{A}, \mathrm{B}$ e $\mathrm{C}$, em vermelho, verde e marrom, respectivamente.

Como método complementar, para identificação da mineralogia, a lupa binocular também foi utilizada.

A análise da micromorfologia foi feita através do Microscópio Eletrônico de Varredura marca TESCAN, modelo Vega SBU que opera em alto e baixo vácuo já equipado com o microanalisador EDS Bruker (MEV-EDS).

Foram selecionados pequenos torrões de cada uma das amostras para serem submetidos ao MEV. O feixe de elétrons gerado por efeito termo iônico é acelerado através de uma diferença de potencial e colimado através de uma coluna óticoeletrônica sendo conduzida à câmara que contém a amostra (Monteiro, 2017). De acordo com a autora, ao focalizar em um ponto da amostra, este feixe de elétrons gera sinais que são captados e amplificados fornecendo um sinal elétrico. Por fim, este sinal gera a imagem.

Neste trabalho o detector de Raios-X utilizado será o EDS. Esse procedimento foi realizado três vezes para cada amostra, totalizando três aumentos diferentes. A primeira corresponde ao aumento mínimo para cada amostra; o segundo aumento foi o mais próximo de $300 \mathrm{x}$ e o terceiro aumento foi o mais próximo de $1000 \mathrm{x}$.

Ambas as análises foram realizadas no Laboratório de Metalurgia do Instituto Federal de Educação, Ciência e Tecnologia do Sudeste de MG (IFET) - Campus Juiz de Fora.

\section{Caracterização da área de estudo}

Para a análise de materiais de intemperismo todo o quadro físico das áreas de estudo é importante. Por isso, a imagem a seguir (Figura 4) apresenta o mapa de Litologia (a), Declividade (b), Pedologia (c), Hidrografia(d), Cobertura do solo (e) e Hipsometria (f) da cidade de Juiz de Fora, onde estão demarcados os pontos estudados neste trabalho seguidas da legenda (Figura 5). Posteriormente tem-se o detalhamento de cada mapa. 

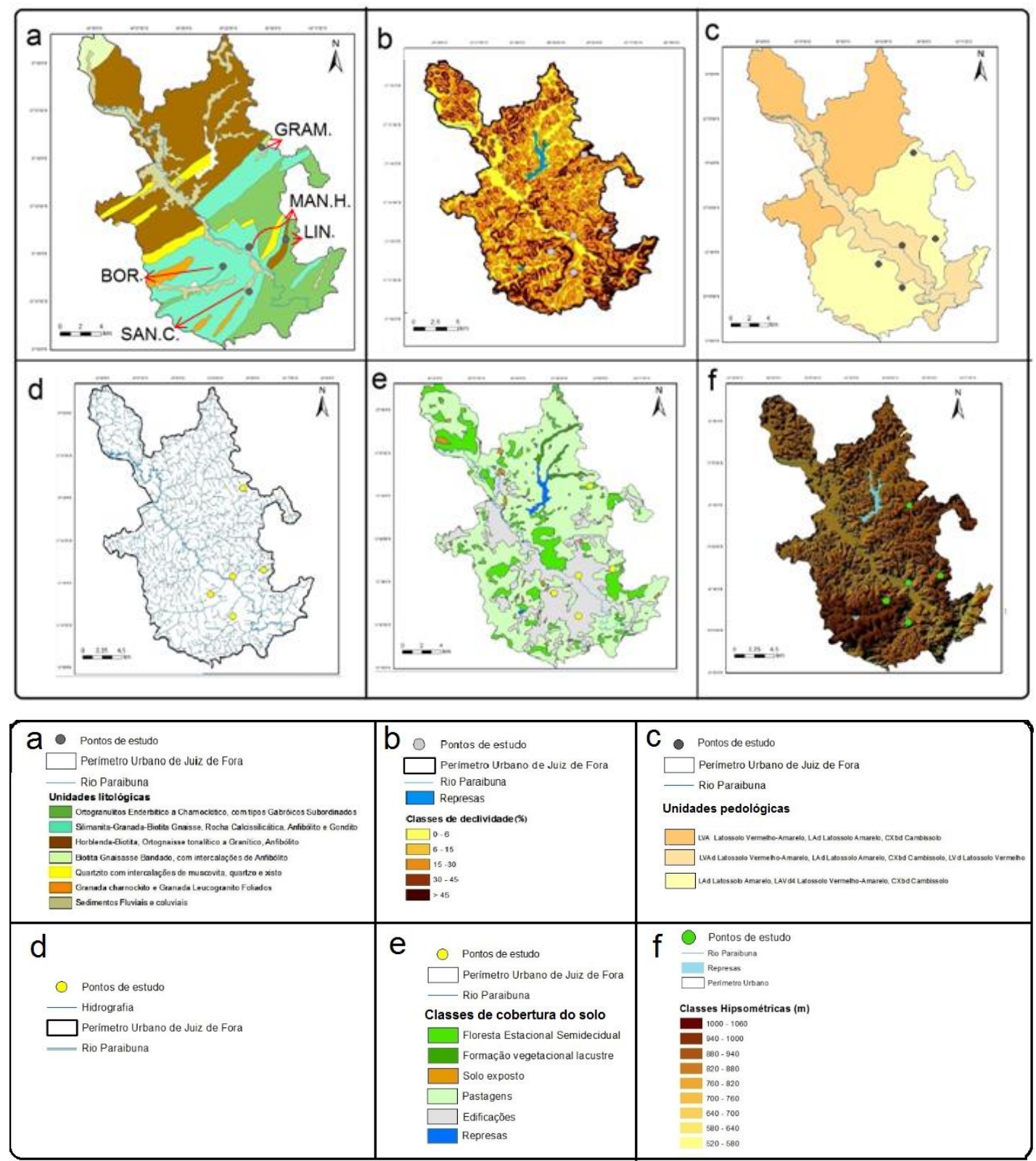

Figuras 4 e 5. Mapas e respectivas legendas de Litologia (a), Declividade (b), Pedologia (c), Hidrografia(d), Cobertura do solo (e), Hipsometria (f) do perímetro urbano de Juiz de Fora com destaque para os pontos de estudo. (Sistema de Coordenadas: UTM; Datum: SIRGAS 2000). Fonte: Dados cartográficos: IBGE (2020); PJF (2017); IGAM (2020)/ Elaboração: Próprios autores.

Como pode ser visto no mapa a da figura 4 Juiz de Fora está inserida em três unidades geológicas, o Complexo Juiz de Fora, o Complexo Mantiqueira e o Grupo Andrelândia. No complexo Juiz de Fora predominam rochas ortogranulíticas e ortognáissicas com intercalações metassedimentares e granitos (Heilbron, 1995; Duarte, 1998). No Complexo Mantiqueira há ortognaisses tonalíticos a graníticos, bandados e migmatíticos, com lentes de metabasitos associados e ortogranulitos enderbíticos e aplitos graníticos cinzentos e rosados (Duarte, 1998). Associações granitogreenstone do Complexo
Barbacena com granito migmatítico-granuliticos do grupo Mantiqueira; um conjunto metassedimentar associado a biotita gnaisses bandados e biotita-granada gnaisses; ortognáisses migmatíticos, com rochas granulíticas, rochas ultramáficas e anfibólitos, constituindo uma associação de alto grau metamórfico representam o Grupo Andrelândia (Heilbron et. al, 1995). Os pontos estudados estão demarcados no mapa de litologia do perímetro urbano de Juiz de Fora (figura 4).

De acordo com o mapa e com informações já estudadas em Paula e Rocha (2020) e Paula e

Paula., R., T., Rocha., G., C. 
Rocha (2019), três (BOR, MAN.H. e SAN.C.) dos cinco perfis estudados estão assentados sobre Biotita Gnaisse do Grupo Andrelândia. O ponto GRAM está inserido sobre quartzito com intercalações de muscovita, quartzoe xisto também do Grupo Andrelândia; e o ponto LIN tem como litologia indicada no mapa Horblenda-Biotita, Ortognaisse tonalítico a Granítico ou Anfibólito da formação Andrelândia.

Em Juiz de Fora as declividades são, em geral, elevadas (Eduardo, 2018), como pode ser visto no mapa $b$ da figura 4 . Isso confere aos diferentes setores das encostas, diferentes distribuições de água, e, consequentemente, diferentes tipos e intensidades de intemperismo e erosão. A figura 4 destaca a declividade em Juiz de Fora e os pontos de estudo.

Os perfis estudados estão situados em locais de média a alta declividade. Destaca-se que os dois perfis situados em áreas de maior declividade são os mesmos assentados soblitologia quartzítica. Os outros três pontos situados em áreas de média declividade estão sob litologias gnáissicas.

De acordo como mapade pedologia (mapa c da figura 4), na região predominam Latossolos vermelho-amarelos, amarelos e vermelhos e Cambissolos. Além destes, Campos (2018) reconhece a presença de Cambissolos Háplicos, Neossolos Flúvicos e Litólicos e Gleissolos.

Segundo o mapa os pontos GRAM, LIN, BOR e SAN.C. estão inseridos em Latossolo Amarelo, Latossolo Vermelho-amarelo ou Cambissolo. O ponto MAN.H. está inserido onde pode haver essas mesma tipologias, incluindo-se o Latossolo Vermelho. Apesar de estar aparentemente próximo do Rio Paraibuna, o ponto não está em contato com nenhum curso de água e não está inserido em nenhuma planície fluvial.

A cidade está inserida na Bacia Hidrográfica do Rio Paraibuna, que apresenta um percurso sinuoso, padrão de drenagem dendrítico e planície fluvial com larguras que podem alcançar 2 km (IGAM, 2011).

Os pontos de estudo estão localizados nos trechos médio e alto do relevo, distantes daplanície fluvial, mas próximos de cursos d'água. O quadro hidrológico da cidade pode está apresentado no mapa da figura 4 .
A vegetação original da cidade foi intensamente alterada, ficando restrita somente a algumas áreas isoladas. A vegetação originária corresponde à Floresta Estacional Semidecidual (Assis et. al, 2011). Nas áreas alteradas predominam pastagens, áreas edificadas e solo exposto. Por isso, o mapa de uso e ocupação do solo foi produzido e apresentado na figura 4.

Os pontos MAN.H., BORB e SAN.C. se localizam em áreas de influência urbana, o ponto GRAM está localizado numa das áreas remanescentes de Floresta Estacional Semidecidual. Já o ponto LIN está inserido numa área de pastagem.

O clima da cidade é úmido de verões brandos. Apresenta duas estações bem definidas, uma fria e seca e outra quente e chuvosa (Duarte,1998). Por apresentar influência altimétrica, o clima pode ser definido também como Tropical de Altitude, sendo que o relevo local apresenta altitudes médias entre 700 e $900 \mathrm{~m}$, que contribuem para a amenização das temperaturas (Torres e Martins, 2005). O mapaf da figura 4 apresenta os pontos de estudo inseridos sobre o mapa de hipsometria da área urbano, fator que pode interferir no microclima da cidade.

Os pontos SAN.C e MAN.H. estão situadas em média altitude, já os pontos BOR, GRAM e LIN se localizam em locais com as maiores altitudes.

\section{Resultados e discussão}

Cada amostra será detalhada a seguir através das fotos de campo e das amostras de mão; do diagrama de difração; do gráfico de porcentagem dos constituintes minerais; das imagens do Microscópio Eletrônico de Varredura; e de um compilado com os resultados das análises físicas

Bairro Grama

As figuras 6, 7 e 8, apresentam, respectivamente fotos de campo e das amostras de mão; o diagrama de difração; o gráfico de porcentagem dos constituintes minerais; as imagens do Microscópio Eletrônico de Varredura; e a tabela 3 traz um compilado dos os resultados das análises das amostras do bairro Grama. 


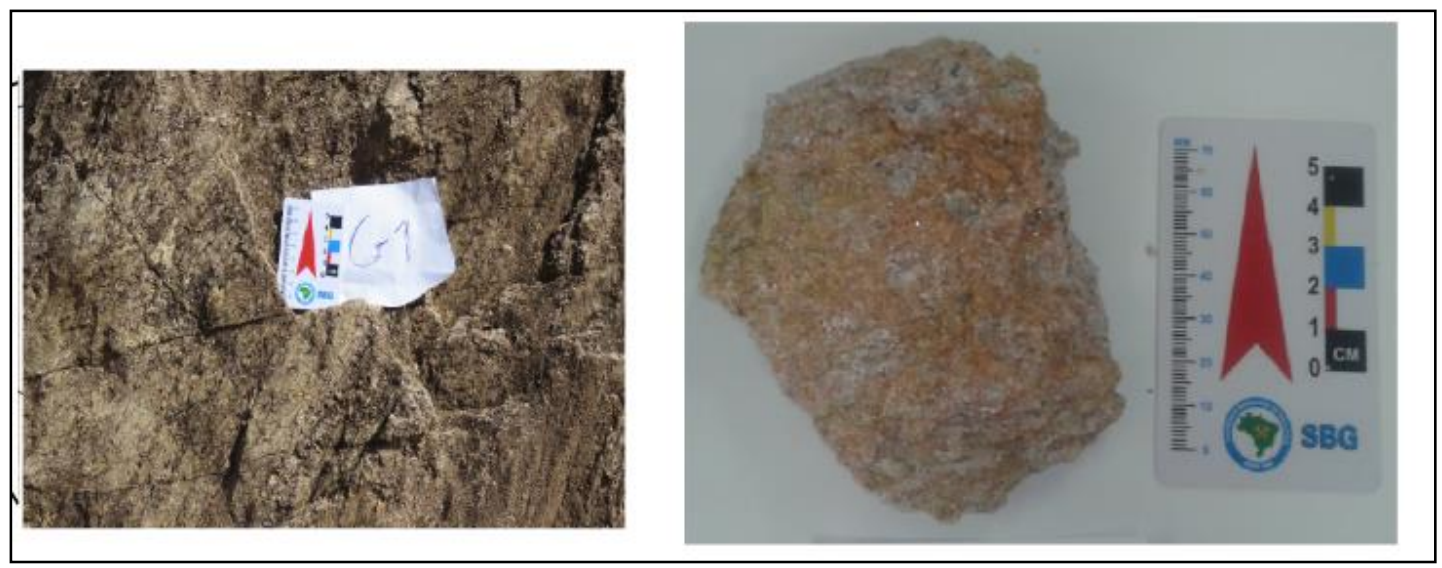

Figura 6. Fotos de campo e da amostra de mão (GRAM).

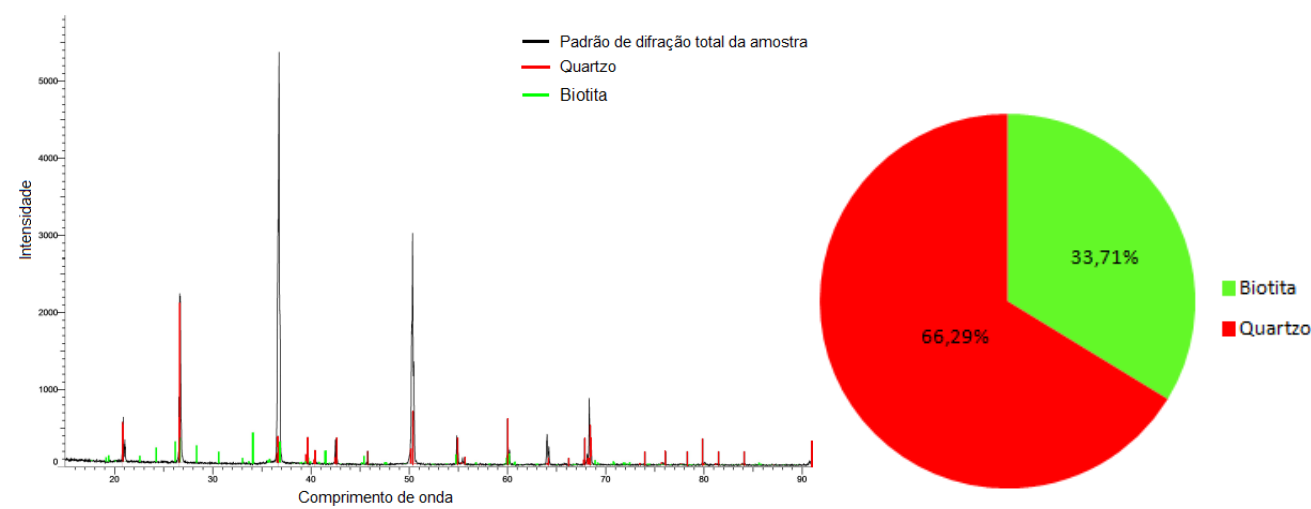

Figura 7. Diagrama de difração de Raios-X e gráfico de porcentagem de minerais (GRAM).
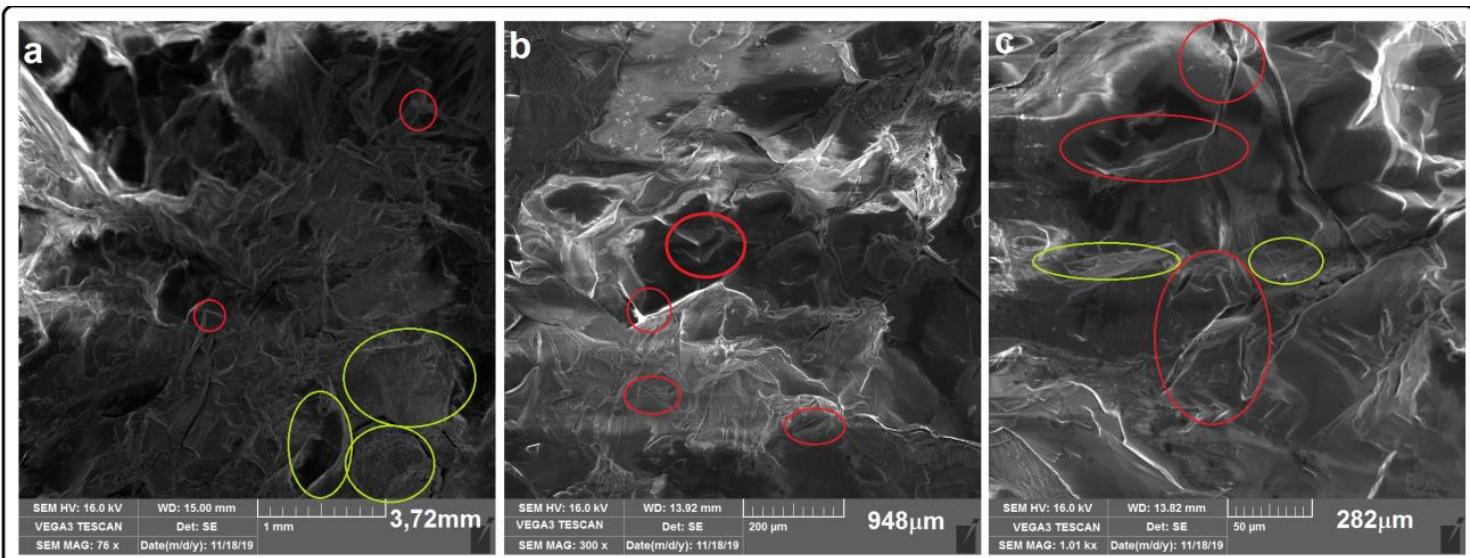

Possíveis vértices de grãos de quartzo

Possíveis lâminas de biotita

Figura 8. Imagens do MEV (GRAM) com aumento de 76x (a), 300x, (b) e 1000x (c).

Tabela 3 - Síntese dos resultados (GRAM)

\begin{tabular}{|c|c|c|c|c|c|c|}
\hline $\begin{array}{l}\text { PONT } \\
\text { O }\end{array}$ & $\overline{C O R}$ & $\begin{array}{c}\text { TEXTUR } \\
\text { A }\end{array}$ & $\begin{array}{c}\text { MINERALOGI } \\
\text { A }\end{array}$ & $\begin{array}{c}\text { CONSISTÊNCI } \\
\text { A }\end{array}$ & $\begin{array}{l}\text { ROCHA } \\
\text { DE } \\
\text { ORIGEM } \\
\end{array}$ & $\begin{array}{c}\text { GRAU DE } \\
\text { ALTERAÇÃO }\end{array}$ \\
\hline $\begin{array}{l}\text { GRAM } \\
\text { (Bairro } \\
\text { Grama) }\end{array}$ & $\begin{array}{c}\text { Rosado / } \\
\text { Branco / } \\
\text { Amarelo } \\
\text { avermelhado }\end{array}$ & Arenosa & Quartzo, biotita & Macia & Quartzito & Muito alterado \\
\hline
\end{tabular}

Paula., R., T., Rocha., G., C. 
A amostra GRAM apresenta coloração heterogênea definida, principalmente, pela cor de cada mineral constituinte. Como constituintes minerais apresenta o quartzo em abundância e a biotita, em menor quantidade. Essa mineralogia confere ao material uma textura grosseira, bastante arenosa e, por ser facilmente desagregada, uma consistência considerada macia.

Destaca-se a inexistência de minerais de argila, que pode ser pela ausência de minerais como o feldspato, que se intemperizam em argilas. $\mathrm{O}$ material de textura grosseira tende a apresentar boa drenagem e, dessa forma, "perder" a pequena quantidade de minerais secundários formados, além disso, apresenta boa condutividade de água, baix a capacidade de retenção de água; boa aeração; geralmente baixo teor de nutrientes, baixa capacidade de adsorção; facilidade de enraizamento; e é fácil de ser trabalhado (Schroeder, 2017; Tullio, 2019).
Embora não tenha sofrido pedogênese e ter os minerais primários bem preservados, o material foi classificado como muito alterado, onde o perfil foi bastante intemperizado, mas manteve o mineral mais resistente preservado, o quartzo. Pela localização e pela caracterização, o material é resultado do intemperismo de quartzitos.

As imagens produzidas pelo MEV mostram que a micromorfologia da amostra é também grosseira, sendo possível observar a presença das lâminas da biotita e um material mais grosseiro, provavelmente o quartzo.

\section{Bairro Linhares}

As figuras 9, 10 e 11, apresentam, respectivamente fotos de campo e das amostras de mão; o diagrama de difração; o gráfico de porcentagem dos constituintes minerais; as imagens do Microscópio Eletrônico de Varredura; e a tabela 4 traz um compilado dos os resultados das análises do Bairro Linhares.

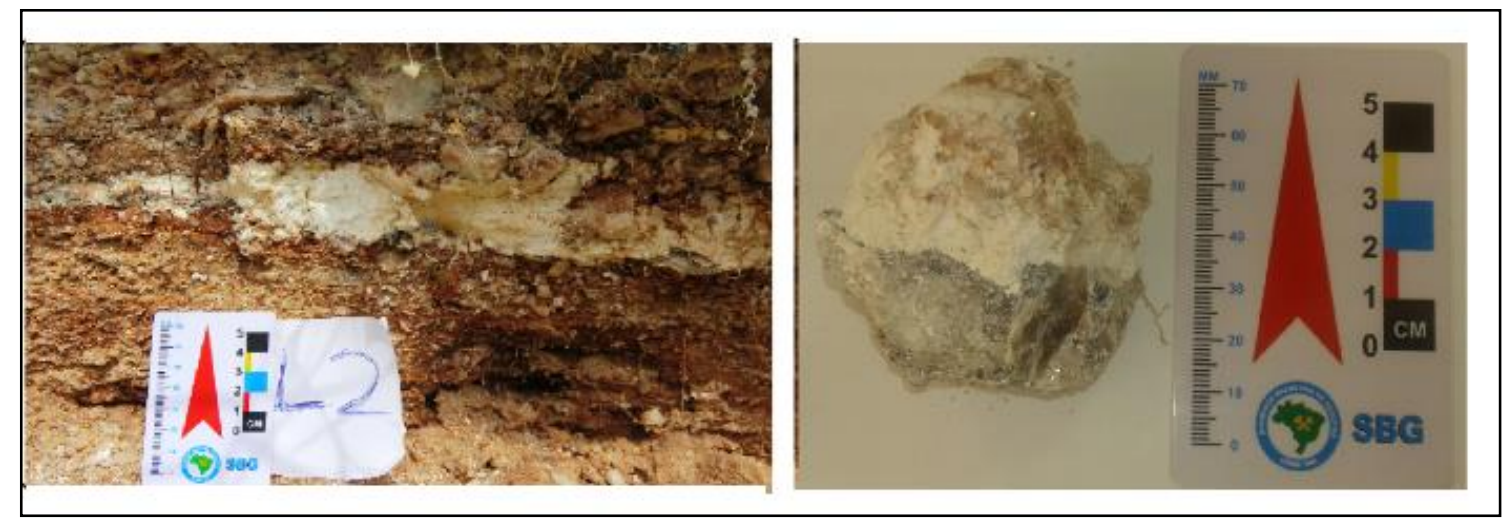

Figura 9. Fotos de campo e da amostra de mão (LIN).
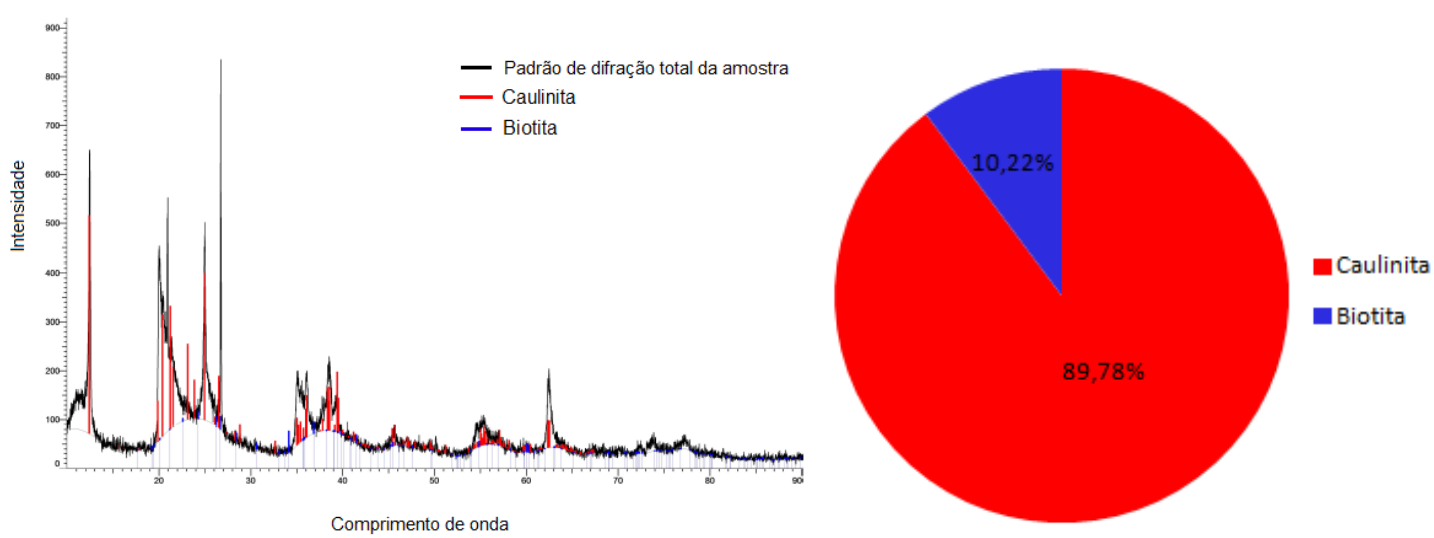

Figura 10. Diagrama de difração de Raios-X e gráfico de porcentagem de minerais (LIN).

Paula., R., T., Rocha., G., C. 


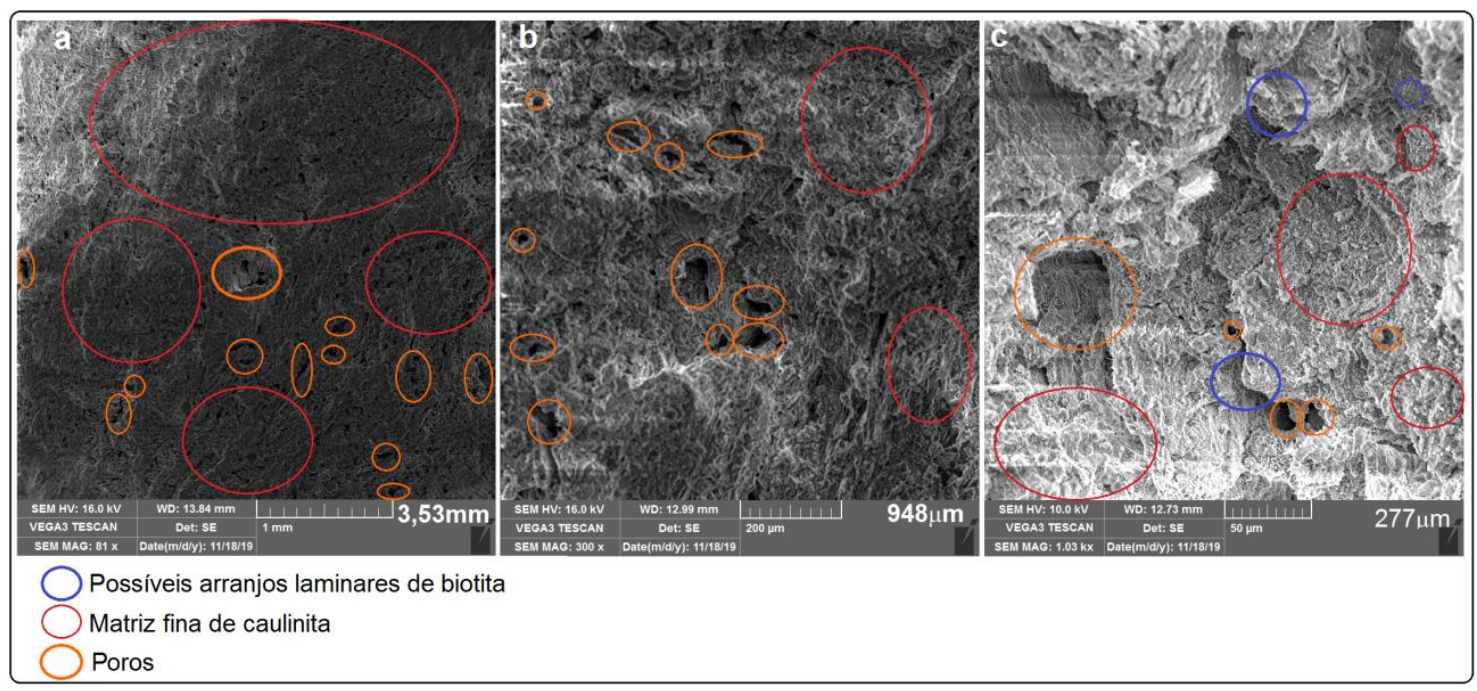

Figura 11. Imagens do MEV (LIN) com aumento de 81x (a), 300x, (b) e 1000x (c).

Tabela 4 - Síntese dos resultados (LIN).

\begin{tabular}{|c|c|c|c|c|c|c|}
\hline PONTO & COR & TEXTURA & MINERALOGIA & CONSISTÊNCIA & $\begin{array}{c}\text { ROCHA } \\
\text { DE } \\
\text { ORIGEM } \\
\end{array}$ & GRAU DE ALTERAÇÃO \\
\hline $\begin{array}{c}\text { LIN } \\
\text { (Bairro } \\
\text { Linhares) }\end{array}$ & $\begin{array}{l}\text { Branco/ } \\
\text { Cinzento }\end{array}$ & $\begin{array}{l}\text { Arenosa na } \\
\text { mica e no } \\
\text { quartzo e } \\
\text { Argilosa na } \\
\text { Caulinita } \\
\end{array}$ & $\begin{array}{c}\text { Biotita, caulinita, } \\
\text { quartzo }\end{array}$ & Variável & $\begin{array}{c}\text { Não } \\
\text { identificada }\end{array}$ & $\begin{array}{c}\text { Completamente alterado na } \\
\text { caulinita e fracamente alterado } \\
\text { na mica e no quartzo }\end{array}$ \\
\hline
\end{tabular}

A amostra LIN tem, entre os materiais analisados neste trabalho, maior heterogeneidade, perceptível no perfil em campo e nas amostras de mão. O difratômetro de Raios-X identificou quase $90 \%$ de caulinita e pouco mais de $10 \%$ de biotita. Macroscopicamente nota-se também a presença de quartzo. Esses minerais são os responsáveis pela variedade da coloração e textura do material, separando-os em dois grupos, um composto pela biotita e pelo quartzo, sendo um material mais arenoso e francamente alterado e outro formado pela caulinita, de textura argilosa e alterado completamente. No perfil esses dois grupos estão separados de forma brusca e bem demarcada.

As imagens do MEV mostram uma matriz mais fina, diferentemente da amostra GRAM. Essa matriz fina corresponde à faixa do perfil constituída pela caulinita. É possível observar também alguns arranjos laminares, possivelmente da biotita. Destaca-se o grande número de poros, o que indica um estágio avançado do intemperismo.

Segundo (Gonçalves, 2018), macro e microporosidades, estabilidade de agregados, infiltração da água, resistência do solo à penetração, entre outros atributos físicos, podem ser utilizados para análise da estrutura do solo.

Bairro Manoel Honório

As figuras 12 e 13, apresentam, respectivamente fotos de campo e das amostras de mão; as imagens do Microscópio Eletrônico de Varredura; e a tabela 5 traz um compilado dos resultados das análises do bairro Manoel Honório.

Paula., R., T., Rocha., G., C. 


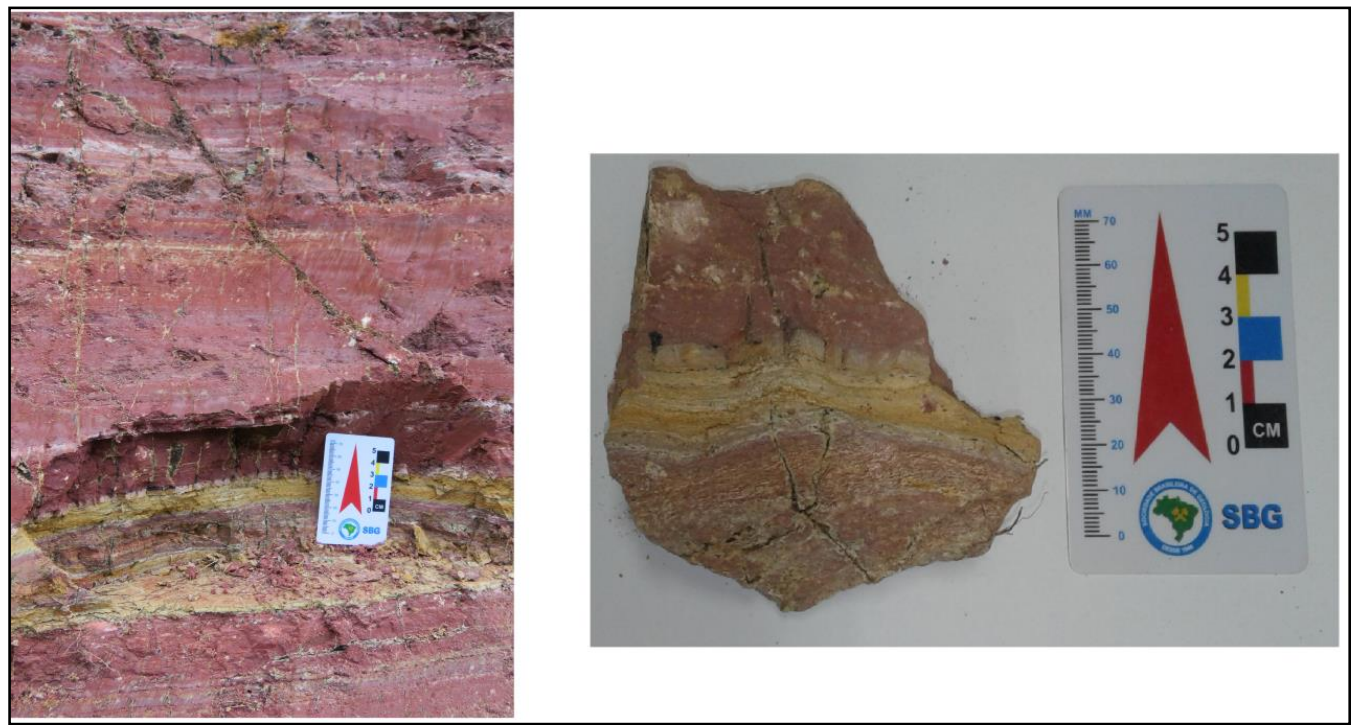

Figura 12. Fotos de campo e da amostra de mão (MAN.H).

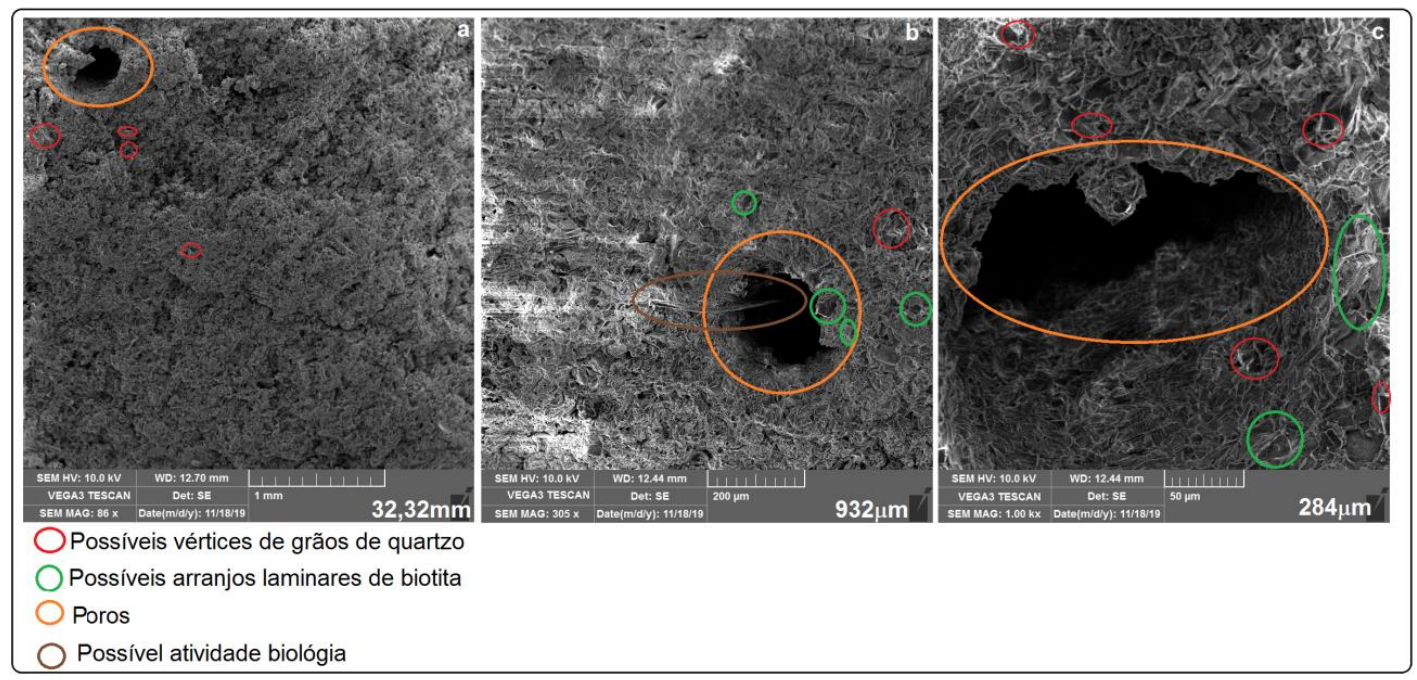

Figura 13. Imagens do MEV (MAN.H.) com aumento de 86x (a), 305x, (b) e 1000x (c).

Tabela 5 - Síntese dos resultados (MAN.H.).

\begin{tabular}{|c|c|c|c|c|c|c|}
\hline PONTO & COR & TEXTURA & MINERALOGIA & CONSISTÊNCIA & $\begin{array}{l}\text { ROCHA } \\
\text { DE } \\
\text { ORIGEM }\end{array}$ & GRAU DE ALTERAÇÃO \\
\hline $\begin{array}{c}\text { MAN.H. } \\
\text { (Bairro } \\
\text { Manoel } \\
\text { Honório) }\end{array}$ & $\begin{array}{c}\text { Bruno/ } \\
\text { Amarelo/ } \\
\text { Cinzento }\end{array}$ & Argilosa & Quartzo, Biotita & Dura & $\begin{array}{l}\text { Biotita- } \\
\text { Gnaisse }\end{array}$ & Muito alterado \\
\hline
\end{tabular}

A amostra MAN.H. é uma amostra fracamente alterada, sendo considerada um material em início de alteração em alguns pontos isolados em meio à matriz rochosa. Os pontos com indício de início de alteração foram submetidas à análise de Raios-X, no entanto, não foi possível realizar a leitura pelo Difragrama por ser uma amostra de consistência inquebrável e, consequentemente, ilegível, já que essa análise exige o procedimento de pulverização da amostra. A análise macroscópica revela que a o quartzo e a biotita formam a principal constituição mineralógica da amostra e corresponde a uma amostra de biotita-gnaisse em início de alteração.

Paula., R., T., Rocha., G., C. 
Através das análises do MEV, nota-se a micromorfologia maciça e com a presença de um poro de maior expressão, que indica avanço de intemperismo. No poro onde é possível observar a presença de uma possível atividade biológica, que pode ser indício do início do processo pedológico nos segmentos de maior alteração, considerando que "os organismos na formação do solo (...) são considerados condicionantes para a pedogênese - a ação dos organismos no substrato representa a diferença entre os processos de pedogênese e intemperismo"(Tullio, 2019 b p.4).

\section{Bairro Santa Cecília}

As figuras 14, 15 e 16, apresentam, respectivamente fotos de campo e das amostras de mão; o diagrama de difração; o gráfico de porcentagem dos constituintes minerais; as imagens do Microscópio Eletrônico de Varredura; e a tabela 6 traz um compilado dos os resultados das análises do bairro Santa Cecília.

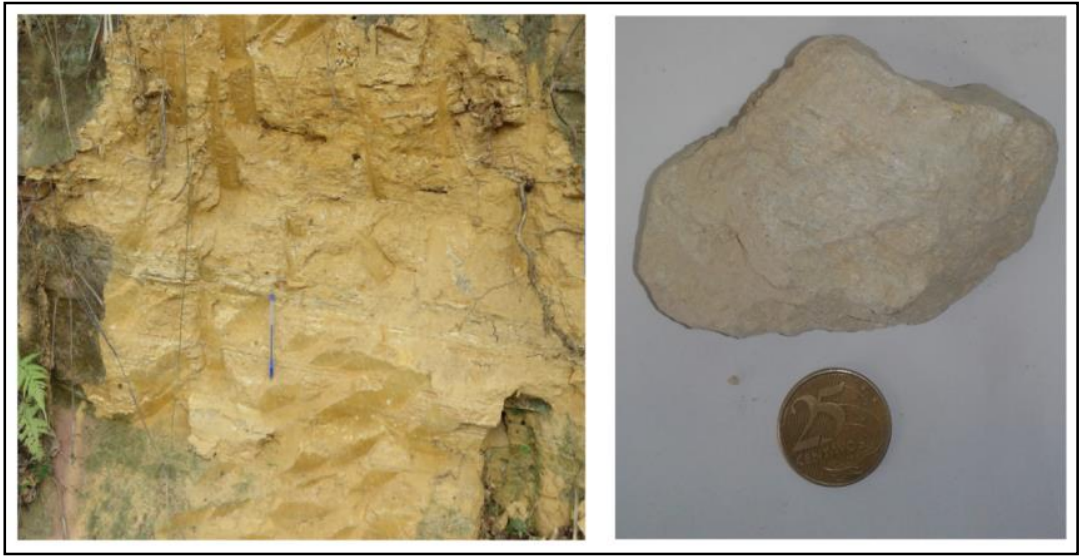

Figura 14. Fotos de campo e da a mostra de mão (SAN.C.).
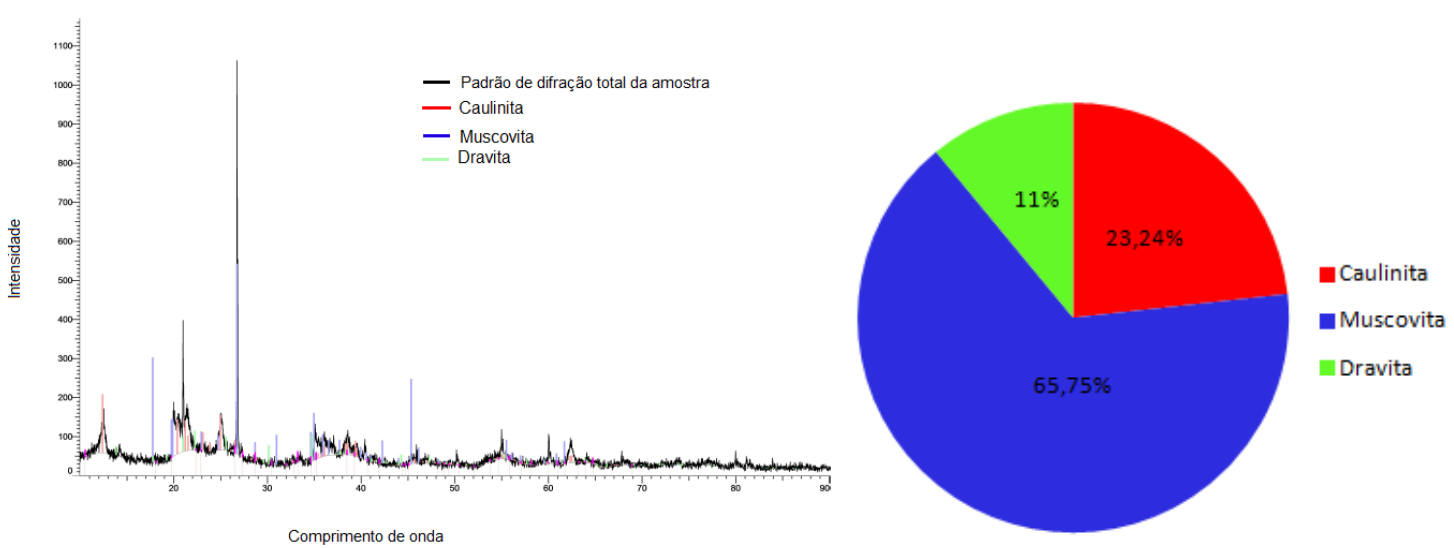

Figura 15. Dia grama de difração de Raios-X e gráfico de porcenta gem de minerais (SAN.C.).

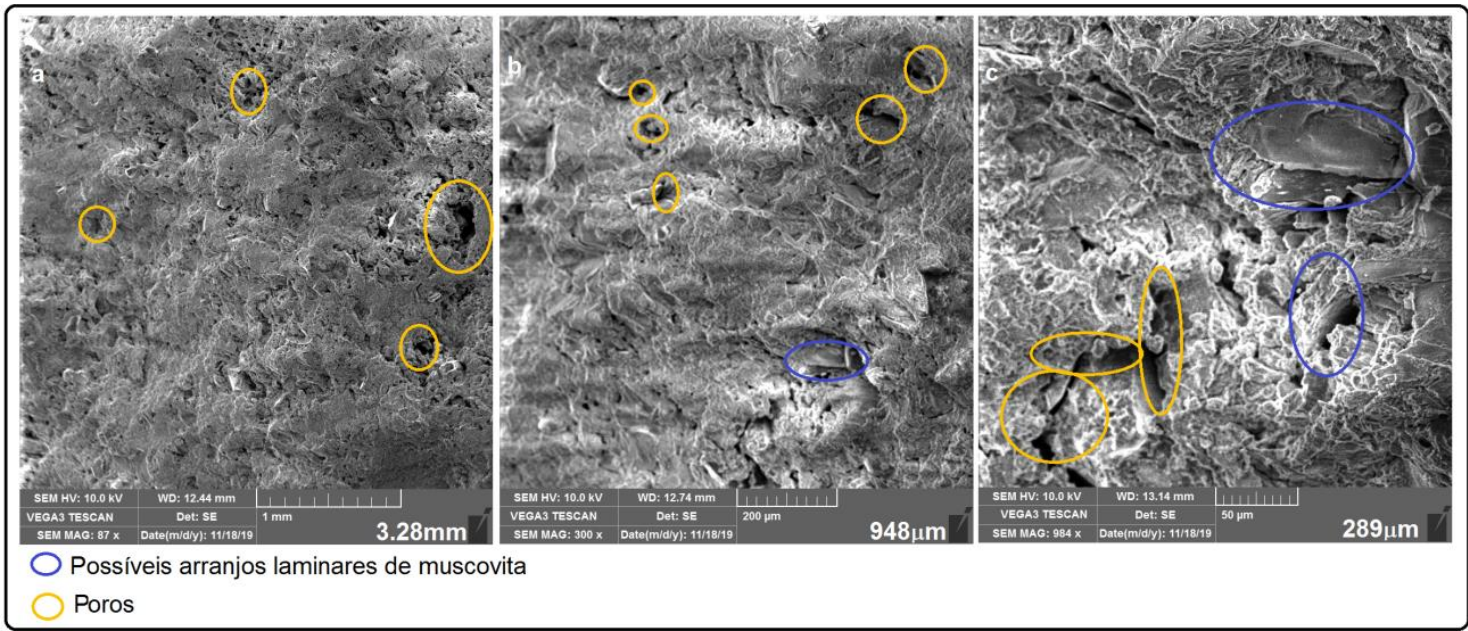

Paula., R., T., Rocha., G., C. 
Figura 16. Imagens do MEV (SAN.C.) com aumento de 87x (a), 300x, (b) e 984x (c).

Tabela 6 - Síntese dos resultados (SAN.C.).

\begin{tabular}{ccccccc}
\hline PONTO & COR & TEXTURA & MINERALOGIA & CONSISTENCIA & $\begin{array}{c}\text { ROCHA } \\
\text { DE } \\
\text { ORIGEM }\end{array}$ & GRAU DE ALTERAÇÃO \\
\hline $\begin{array}{c}\text { SAN.C. } \\
\text { (Santa } \\
\text { Cecília) }\end{array}$ & $\begin{array}{c}\text { Amarelo } \\
\text { Acinzentado }\end{array}$ & Argiloso & $\begin{array}{c}\text { Caulinita, } \\
\text { Auscovita e } \\
\text { Dravita }\end{array}$ & Macia & Gnaisses & Muito Alterado \\
\hline
\end{tabular}

$\mathrm{Na}$ amostra SAN.C. predomina o mineral muscovita (que confere "faixas" acinzentadas ao perfil), em seguida a caulinita (amarelada), e, em menor porcentagem, a dravita, uma variedade do mineral turmalina. É um material de matriz argilosa caulinítica, com pontos bem demarcados da muscovita em meio a argila. É considerado muito alterado por conta do estágio avançado de intemperismo devido à presença de caulinita. $\mathrm{O}$ intemperismo neste perfil ocorreu de forma a preservar a orientação bandada dos minerais, que, de acordo com as análises, corresponde a um gnaisse do tipo Anfibólito.

Percebe-se nas imagens geradas pelo $\mathrm{MEV}$, uma microestrutura maciça, com a matriz argilosa e a presença de alguns microporos. Além disso nota-se a presença de lâminas bem definidas que possivelmente correspondem à muscovita, mineral de arranjo laminar constatado pelo difratômetro de Raios-X.

\section{Bairro Borboleta}

As figuras 17, 18 e 19, apresentam, respectivamente fotos de campo e das amostras de mão; o diagrama de difração; o gráfico de porcentagem dos constituintes minerais; as imagens do Microscópio Eletrônico de Varredura; e a tabela 7 traz um compilado dos os resultados das análises do bairro Borboleta

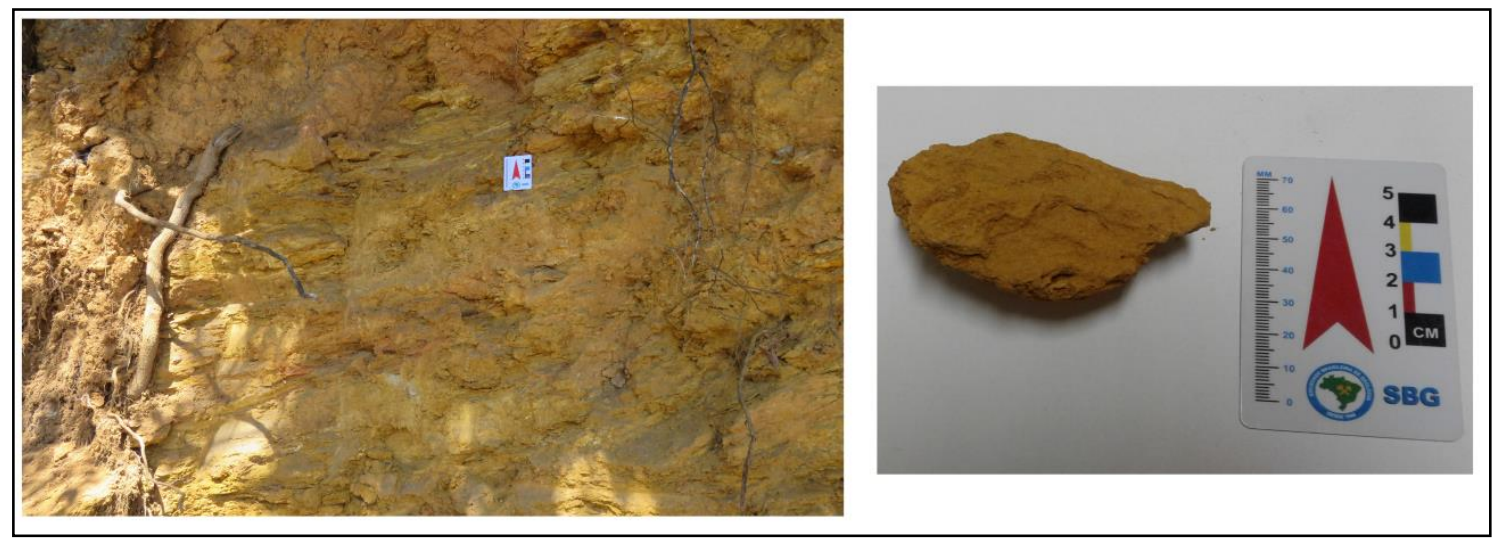

Figura 17. Fotos de campo e da amostra de mão (BOR).
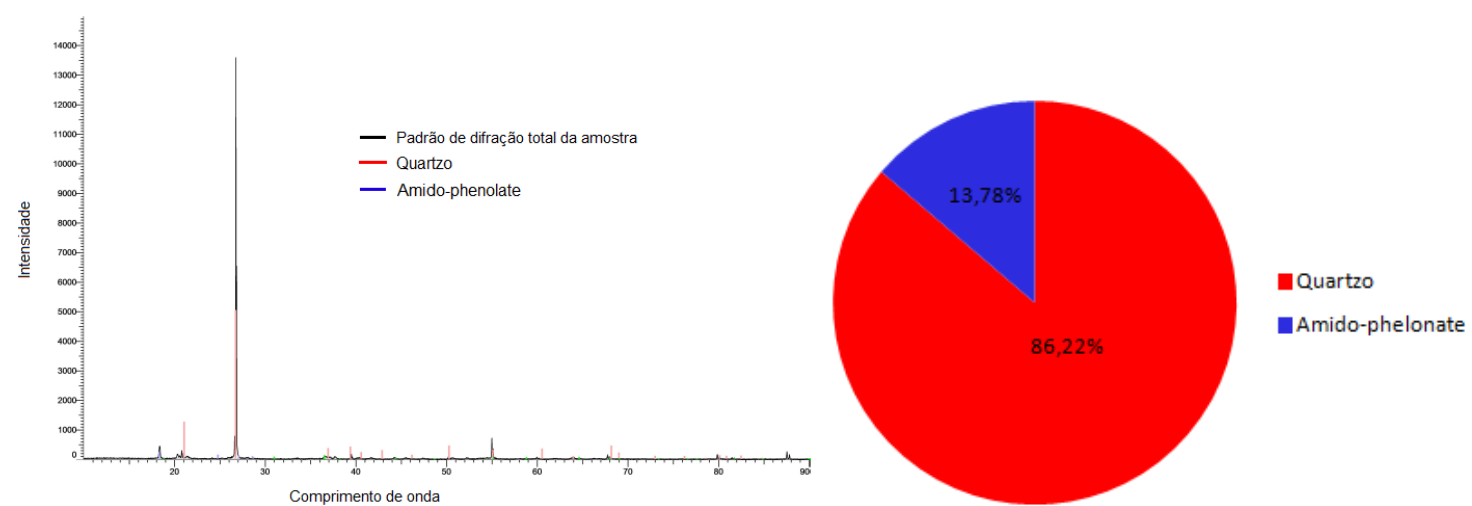

Figura 18. Dia grama de difração de Raios-X e gráfico de porcentagem de minerais (BOR).

Paula., R., T., Rocha., G., C. 


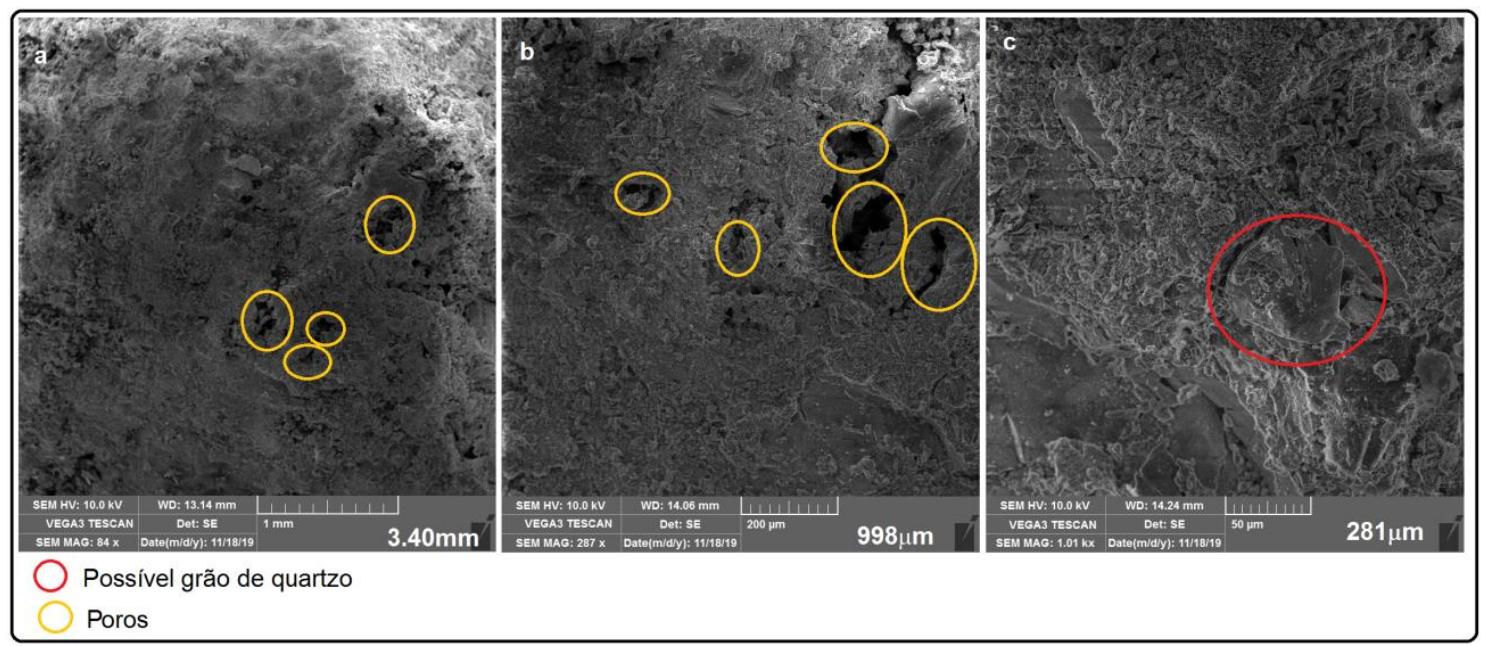

Figura 19. Imagens do MEV (BOR) com aumento de 84x (a), 287x, (b) e 1001x (c).

Tabela 7 - Síntese dos resultados (BOR).

\begin{tabular}{|c|c|c|c|c|c|c|}
\hline PONTO & COR & TEXTURA & MINERALOGIA & CONSISTENCIA & $\begin{array}{c}\text { ROCHA } \\
\text { DE } \\
\text { ORIGEM }\end{array}$ & $\begin{array}{c}\text { GRAU DE } \\
\text { ALTERAÇÃO }\end{array}$ \\
\hline$\overline{\text { BOR }}$ & $\begin{array}{c}\text { Amarelo } \\
\text { avermelhado } \\
\text { / Bruno } \\
\text { escuro }\end{array}$ & $\begin{array}{l}\text { Areno- } \\
\text { argilosa }\end{array}$ & Quartzo & Muito Dura & $\begin{array}{l}\text { Biotita- } \\
\text { Gnaisse }\end{array}$ & Muito alterado \\
\hline
\end{tabular}

A difratometria de Raios-X indicou para a amostra BOR a presença predominante de quartzo. O outro constituinte registradoé o amido-phelonate em pequena quantidade, composto de um dos produtos utilizados para tratamento de água e esgoto e que pode ter entrado em contato com o material analisado. O predomínio do quartzo confere ao material uma textura arenosa. A amostra foi considerada muito alterada e de consistência muito dura. Isso se deve ao fato de se tratar de um produto de alteração de uma rocha com alta porcentagem de quartzo, um mineral de alta dureza e resistente ao intemperismo.

As imagens do MEV indicam alguns pontos de estrutura maciça, sem a presença de poros, mas alteração em outros, onde nota-se o aparecimento de algumas cavidades, que podem indicar focos de alteração.

\section{Conclusão}

As análises física, macro e microscópica, e mineralógica são técnicas importantes e auxiliam na caracterização de materiais de intemperismo.

A cor do material é variável entre e intra amostras, e é dependente de cada mineral constituinte. A cor do produto de alteração tende a se homogeneizar à medida que o material se intemperiza, mas mantém uma variação agrupada em minerais de diferentes resistências, até a completa alteração.

A textura está diretamente ligada aos minerais constituintes e seus tamanhos, que por sua vez, são dependentes de seus graus de alteração. A consistência é dependente da resistência dos minerais constituintes e da alteração do perfil, podendo ser variável de acordo com o grau de alteração, sendo que quanto mais alterado mais macio.

As rochas de origem identificadas foram o quartzito e o gnaisse. Em duas amostras não foi possível a identificação pois o material se encontra em um grau de alteração significativo e o litotipo indicado no mapa não condiz com a mineralogia encontrada.

Os principais minerais encontrados nos perfis estudados foram quartzo, biotita, muscovita e caulinita. Nota-se que quanto maior a porcentagem de argila, menor a consistência e maior o grau de alteração. A presença de caulinita foi constatada onde consta que o material de origem é o gnaisse e ausente onde o material de origem é o quartzito.

Apesar de ser constituído predominantemente por quartzo, um mineral resistente ao intemperismo, a amostra que provém 
da alteração de quartzito apresenta alto grau de alteração. O quartzo está bem preservado, mas o perfil se encontra num estado de alteração elevada. Isso mostra que a presença de minerais primários mais resistentes nãoimpede a alteração do perfil. A presença de minerais mais resistentes tende a dificultar o processo de pedogênese, resultando em perfis mais arenosos, com poucos minerais de argila e sem a presença de atividade biológica. Nos perfis em que predomina o quartzo, apesar da presença desse mineral, o grau de alteração é elevado.

\section{Agradecimentos}

Agradeço ao Programa de Pós Graduação em Geografia da Universidade Federal de Juiz de Fora pela oportunidade de cursar o Mestrado; ao meu orientador, Geraldo pelos conhecimentos passados; à CAPES, pelo fornecimento da bolsa de pós graduação; ao Laboratório de Metalurgia do Instituto Federal de Juiz de Fora pelo auxílio nas análises.

\section{Referências}

Assis, D. C. ; Oliveira, D. E. ; Ferreira, C. C. M., 2018. Levantamento das Áreas Vegetadas para a Análise da Temperatura do ar: Um Estudo de Caso dos Bairros Benfica e Centro, Juiz de Fora, MG. XIV Simpósio Brasileiro de Geografia Física Aplicada: Dinâmicas SocioAmbientais, das inter-relações às interdependências, 01,0114.

Barros, F. B. M. de, 2019. Caracterização dimensional, morfológica e estrutural de partículas de calcário e dolomito cominuídas em moinho planetário e o estudo da aglomeração de ultrafinos. Dissertação (Mestrado em Ciências). Universidade federal de Pernambuco, Recife, PE, 107.

Beckhoff, B.; Kanngieber, B.; Langhoof, N.; Wedell, R.; Wolff, H., 2006. Handbook of Practical X-Ray Fluorescence Analysis, 1 ed., Berlin-London, Springer.

Berisavljević, D., Berisavljević, Z., 2019. Determination of the presence of microstructure in a soil using a seismic dilatometer. Bulletin of Engineering Geology and the Environment 78, 1709-1725.

Brizzi, R. R.; Portocarrero, H.; Souza, A. P. de; Costa, A. J. S. T. da; Rangel, L. de A., 2019. Avaliação macro e microestrutural de solos sob diferentes usos a partir de análises físicas, microscopia eletrônica e espectroscopia por energia dispersiva, Raega - O Espaço Geográfico em Análise, v. 46, n. 1, 25-40.

Camargo, O. A.; Moniz, A. C.; Jorge, J. A.; Valadares, J. M. A. S., 1986. Métodos de análise química, mineralógica e física de solos, do Instituto Agronômico de Campinas, (Boletim Técnico).

Costa, D. G. da, 2015. Caracterização de solos tropicais com diferentes texturas para estudos de volatilização do herbicida 2,4-D. Dissertação (mestrado em Engenharia Civil), PUC-Rio Pontifícia Universidade Católica, Rio de Janeiro,.

De Castro, S. \& Cooper, M., 2019. Fundamentos de Micromorfologia. Sociedade Brasileira de Ciência do Solo, 240.

Dedavid, B. A.; Gomes, C. I. ; Machado, G., 2007. Microscopia Eletrônica de VarreduraAplicações e preparação de amostras. EDUPUCRS 1. Ed, v. 1, Porto Alegre, 60 p.

Duarte, B. P., 1998. Evolução tectônica dos Ortognaisses dos complexos Juiz de Fora e Mantiqueira na região de Juiz de Fora, MG, Geologia, Petrologia e Geoquímica. Tese (Doutorado em Geoquímica e Geotectônica), Universidade de São Paulo, São Paulo.

Eduardo, C. C., 2018. Cartografia geomorfológica comparada: aplicações no município de Juiz de Fora (MG) como subsídio ao planejamento. Dissertação (Mestrado em Geografia), Universidade Federal de Juiz de Fora, Juiz de Fora.

Fonseca Filho, H. D. Da; Lopes, G. A. C., 2013. Avanços em caracterização de amostras sólidas cristalinas através de difratometria de Raios-X. Estação Científica (Macapa), 3, 31-45.

Frazão, E. B., 2012. Alteração de rochas como critério de seleção de agregados. Oficina de Texto, São Paulo, 123 p.

Heilbron, M.; C. Valeriano, C.; Machado, N. A., 1995. Orogênese Brasiliana no Segmento Central da Faixa Ribeira, Brasil. The AdvanceProgress (Vidalia), v. 25, n.4, 32-50.

IGAM, Instituto Mineiro De Gestão das Águas, 2011. Monitoramento da qualidade das águas superficiais no estado de Minas Gerais. Relatório trimestral de 2011. Disponível em: <http://www.igam.mg.gov.br/>. Acesso em: mai. 2020.

IBGE, - Instituto Brasileiro de Geografia e Estatística. Bases e referenciais, 2020. Disponível em $<$ https://mapas.ibge.gov.br/bases-ereferenciais/bases-cartograficas/cartas.html>. Acesso em 2020. 
Jenkins, R.; Snyder, R. L., 1996. Introduction to XRay Powder Diffractometry. Chemical Analysis, John Wiley \& Sons, v.138. 403 p.

Lemos, R. C. de; Santos, R. D. dos; Santos, H.G.; Ker, J.C.; Anjos, L.H.C., 2005. Manual de descrição e coleta de solo no campo. Sociedade Brasileira de Ciência do Solo, $5^{\circ}$ edição, Viçosa.

Mannheimer W.A; Schmidt P.F.; Vander Voort G.F.; Williams D.B., 2002. Microscopia dos Materiais: Uma Introdução. Sociedade Brasileira de Microscopia, 221 p.

Marcolin, L.; Calegari, M. R., 2020. Vista do Atributos químicos, físicos e mineralogia de Latossolos e sua relação com a paisagem no oeste do Paraná. Revista do Departamento de Geografia da Universidade de São Paulo-USP, 39, 48-61.

Monteiro, M. K. S., 2017. Obtenção e caracterização de bionanocompósitos de fécula de mandioca e argila bentonita organofilizada por mistura de tensoativos. Dissertação (Mestrado em Engenharia Química), Universidade Federal do Rio Grande do Norte, UFRN, Rio Grande do Norte.

Gonçalves, L. E. S., 2018. Eficiência do sistema de drenagem adotado na região de mineração de bauxita, na Zona da Mata de Minas Gerais. Dissertação (Mestrado em Ciência Florestal), Universidade Federal de Viçosa, Viçosa, MG, 94 .

Menezes, S. O., 1999. Identificação macroscópica de rochas. Universidade Federal de Juiz de Fora - MG.

Melo Júnior, A. S., 2007. Análise quantitativa do material particulado na região de Campinas através das técnicas de microfluorescência de Raios-X e reflexão total usando radiação síncrotron. Tese (Doutorado em Química), Unicamp, Campinas, São Paulo.

Melton, M. A., 1965. Debris-covered hillslopes of the southern Arizona desert - consideration of their stability and sediment contribution. Jour. Geol., 73, 715-729.

Munsell Soil Color Company, 1975. Munsell color, Macbeth Division of Kollmorgen Corporation, Baltimore, Maryland, USA. 1950, revised 1975.

Oliveira, E. A. de, 2011. Confiabilidade metrológica na determinação de espécies químicas em materiais siderúrgicos por espectrometria de fluorescência de Raios-X. Dissertação (mestrado em Meteorologia), Pontifícia Universidade Católica do Rio de Janeiro - PucRio. Rio de Janeiro.
Ollier, C. D., 1965. Some features of granite weathering. Australia, Zeitschrift Für Geomorphologie, 9, 285-304.

Paula, R. T.; Rocha, G.C., 2020. Análise, caracterização e dinâmica em perfis de intemperismo na área urbana de Juiz de Fora MG. Dissertação (mestrado em Geografia), Juiz de Fora, 116.

Paula, R. T.; Rocha, G.C., 2019. Características do intemperismo em quartzito em domínio Tropical Atlântico. VII Seminário do Programa de Pós Graduação em Geografia (PPGEO UFJF), Juiz de Fora - MG.

PJF - Prefeitura de Juiz de Fora, 2017. Secretaria de Planejamento, setor de Geoprocessamento (Arquivos de gabinete), Juiz de Fora.

Ramos, M. A. B.; Dantas, M. E.; Maia, M. A. M.; Machado, M. F.; Pfaltzgraff , P. A.; Ambrosio, M. F.; Osório, C., 2020. Manual Metodológico para Levantamento da Geodiversidade em escalas 1:100.000 a 1:50.000, Projeto Geodiversidade, 47.

Rocha, B. P., 2018. Caracterização geotécnica de solos tropicais não saturados por meio de ensaios de campo. Tese (Doutorado em Ciência), Programa de Pós-Graduação em Geotecnia, Escola de Engenharia de São Carlos, Universidade de São Paulo, São Carlos, 272.

Rocha, G. C., 2005. Riscos Ambientais: Análise e Mapeamento em Minas Gerais. UFJF, 127 p.

Sarala, P.; Koskinen, H., 2018. Application of the portable X-Ray Diffraction (pXRD) analyser. Surficial Geological Exploration 70, 58-68.

Schroeder, D., 2017. Solos: fatos e conceitos. Traduzido por Alfredo Scheid Lopes. Zug International Potash Institute, 244.

Silva, A. L. da, 2013. Caracterização Mineralógica por Difração de Raios X e Determinação de Terras Raras por ICP-MS de Rochas da Região Sul da Bahia. Dissertação de Mestrado (Ciências Técnicas Nucleares). Universidade Federal de Minas Gerais, UFMG. Belo Horizonte.

Silva, C. E. B., 2015. Estudos Teóricos do Estado Excitado de Moléculas Orgânicas em Solvente. Tese (Doutorado em Física), Universidade de São Paulo, USP, São Paulo.

Thomas, M. F., 1994. Geomorphology in the tropics: a study of weathering and denudation in low latitudes. John Wiley \& Sons, 460 p.

Torres, F. T. P.; Martins, L. A., 2005. Fatores que influenciam na concentração do material 
particulado inalável na cidade de Juiz de Fora, MG. Caminhos da Geografia, v. 16, 23-39.

Tullio, L (Org.), 2019. Características dos solos e sua interação com as plantas. Atena Editora, 176 b, 2019. Formação, classificação e cartografia dos solos. Atena Editora, $126 \mathrm{p}$. Wanderley Neto, R. V., 2020. Estudo experimental de interfaces solo-concretono contexto de solos não saturados. Dissertação (Mestrado em Geotecnia), Universidade de Brasília, UNB, Brasília, 206. 